\title{
Molecular manipulation and modification of the genes encoding the G2 and G4 glycinin subunits
}

\author{
Reda H. Sammour \\ Department of Botany, Faculty of Science, Tanta University, Tanta, Egypt.
}

\begin{abstract}
The genes encoding the glycinin subunits G2 and G4 were molecularly manipulated and modified to test the possibility of increasing the nutritional value of soybean seed proteins. The recombinant DNAs pSP65/G2HG4, pSP65/G4HG2, pSP65/248 Metl, pSP65/248 Met2,3 and pSP65/248 Metl.2,3 were used in in vitro translation to produce (i) chimeric proteins consisting of reciprocally exchanged acidic and basic G2 and G4 domains and (ii) Gy4 point mutants with an increased number of methionine residues. The ability of the recombinant proteins to assemble into proper quaternary structures was investigated using sucrose gradient fractionation. The data produced by this study could provide valuable clues for the potential improvement of genetically modified crops.
\end{abstract}

Key words: cDNA, glycinin subunit G4, in vitro translation, mutagenesis, soybean.

Received: October 25, 2005; Accepted: November 16, 2005.

\section{Introduction}

Glycinins are the predominant storage proteins in soybean seeds where they account for more than $20 \%$ of the seed dry weight in some cultivars and are primarily produced in cotyledon cells where they are sequestered within sub-cellular organelles called protein bodies (Nielsen el al., 1989; Nielsen et al., 1996; Nielsen and Nam, 1999; Vitale and Jurgen, 1999). As isolated from seed extracts, the glycinins are an oligomer of six similar subunits (Badley et al., 1975; Nielsen, 1996; Wang et al., 2003), the properties of which have been extensively reviewed (Moreira et al., 1979; Larkins, 1981; Turner et al., 1981; Chrispeels et al., 1982; Nielsen, 1984; Nielsen et al., 1996; Jung et al., 1998).

Glycinin subunits accumulate rapidly during embryogenesis and this accumulation is associated with dramatic changes in the prevalence of glycinin mRNAs (Nielsen et al., 1989) which begin to accumulate early in embryogenesis, are highly prevalent during the mid-maturation stage and decay prior to seed dormancy (Walling et al., 1986; Goldberg et al., 1989a; Goldberg et al., 1989b). The accumulation and decay of these mRNAs is in part regulated by transcriptional processes similar to those regulating other seed protein mRNAs (Cho et al., 1989; Goldberg et al., 1989a; Beilinson el al., 2002).

The predominant glycinin subunits found in soybeans are encoded by five genes $(G y)$ which have diverged into

Send correspondence to Reda H. Sammour. Department of Botany, Faculty of Science, Tanta University, Tanta, Egypt. E-mail: reda_sammour@yahoo.com. two subfamilies designated as group-1 (Gyl, Gy2, and Gy3) and group-2 (Gy4, Gy5) glycinin genes (Cho et al. 1989 and Nielsen et al., 1989). More recently, Beilinson el al. (2002) identified two new genes, a glycinin pseudogene $(G y 6)$ and a functional gene $(G y 7)$. Even though the ammo-acid sequence of the glycinin G7 subunit is related to the other five soybean 1 IS subunits (soybean legumin like protein), it does not fit into either the group-1 (G1, G2, $\mathrm{G} 3)$ or the group-2 (G4, G5) glycinin subunit families.

Dickinson et al. (1989) developed an in vitro system that allows the self-assembly of group-2 proglycinin subunits into that resemble those found naturally in the endoplasmic reticulum. The self-assembly of group-2 proglycinin into trimers requires post-translation cleavage before they are assembled into hexamers similar to those isolated from the proteins bodies of mature seeds (Nielsen et al., 1996; Jung et al., 1998; Kinney et al., 2001). The ability to synthesize and assemble glycinin complexes in vitro is a useful tool for attempts to engineer subunits which can be assembled into proteins with improved nutritional qualities (Kirn et al., 1990; Utsumi et al., 1993; Katsube et al., 1994; Katsube et al., 1998) and for the identification of regions in the subunits crucial for oligomer formation (Dickinson et al., 1987; Dickinson, 1988; Nielsen, 1990).

Because of the high concentration of glycinin in soybean seeds and its major contribution to the nutritional properties of soybean proteins, combined with the effects of glycinin on the functional properties of food products made from beans this protein has been targeted for genetic manipulation to improve soybean nutritional quality. The 
observation that the G2 subunit, rich in sulfur amino acids, does not self-assemble in vitro could mean that a modified G2 expressed at high level will not assemble efficiently in protein bodies (Dickinson 1988). It also remains to be demonstrated that in vitro and in vivo glycinin assembly occur in the same way, so an alternate and better strategy for improving the nutritional quality of glycinin may be to alter the G4 subunit which is capable of self-assembly.

In the study reported in this paper we constructed three bacterial mutants containing an increased amount of methionine (one to three residues), substitute the acidic subunit of G4 with that of G2 to determine structural features contributing to the different assembly behaviors of the group-1 and group-2 glycinins and test their self-assembly in vitro. Moreover it will shed light on the possibility of engineering transgenic soybean seed with high nutritional quality.

\section{Material and Methods}

Glycinin purification, in vitro synthesis, assembly and labeling

Glycinin was purified according to previously published procedures (Moreira et al., 1979). The in vitro transcription with SP6 RNA polymerase followed by translation with rabbit reticulocyte lysate was accomplished as described by Dickinson et al. (1989). Self-assembly of the proglycinin produced by the bacterial mutants (recombinant DNAs) constructed in this study was carried out as reported by Dickinson (1988).

For re-assembly with labeled protein $8 \mu \mathrm{L}$ of $5 \mathrm{X}$ extraction buffer ( $0.175 \mathrm{M}$ phosphate, $\mathrm{pH} 7.5,2 \mathrm{M} \mathrm{NaCl})$ was vortexed with $40 \mu \mathrm{L}$ of ${ }^{3} \mathrm{H}$-labeled glycinin protein which had been freshly synthesized in reticulocyte lysate after which $40 \mu \mathrm{L}$ of dissociated glycinin $\left(8 \mathrm{mg} \mathrm{mL}^{-1}\right)$ was added and the mixture again vortexed before quickly adding a further $8 \mu \mathrm{L}$ of $5 \mathrm{X}$ extraction buffer and re-vortexing the mixture which was then dialyzed overnight against a mixture containing $35 \mathrm{mM}$ phosphate ( $\mathrm{pH} 7.5), 0.4 \mathrm{M} \mathrm{NaCl}$ and $10 \mathrm{mM}$ 2-mercaptoethanol. After dialysis the solution was diluted with $100 \mu \mathrm{L}$ of $1 \mathrm{X}$ extraction buffer without 2-mercaptoethanol and the re-assembly products loaded onto a sucrose density gradient. For re-assembly with proglycinin trimers the 9S sucrose gradient fraction was dialyzed against $1 \mathrm{X}$ extraction buffer and then mixed directly with dissociated glycinin, the subsequent steps being performed as described above.

\section{Construction of the $p S P 65 / G 4 H G 2$ and pSP65/G2HG4 plasmids}

To constrict plasmids encoding the G2 and G4 chimeric subunits it was necessary to introduce a HindIII site at position 928 (numbering from the initial ATG methionine codon in Gy2 cDNA (Nielsen et al. 1989) into the pMP
$18 / 27$ plasmid which contains $G y 2$ cDNA but lacks the portion encoding the signal sequence. Mutagenesis was performed using the method of Kunkel (1985) and the oligonucleotide pGGCGAAGCTTCATTGTGC. The resulting plasmid was denoted pMP18/MG2H and contained a HindIII site at the appropriate position. A HindIII site exists at an analogous position on the Gy4 cDNA clone pSP65/248 plasmid.

Two plasmids were created encoding chimeric glycinin subunits. The pSP65/G2HG4 plasmid encoded the G2 acidic polypeptide fused to the G4 basic polypeptide and the $p S P 65 / G 4 H G 2$ plasmid encoded the G4 acidic polypeptide fused to the $\mathrm{G} 2$ basic polypeptide. To create pSP65/G2HG4, pSP65/248 was digested with BamHI and partially digested with HindIII. The $3.7 \mathrm{~kb}$ fragment which resulted from this treatment was ligated to the $0.9 \mathrm{~kb} \mathrm{Bam} /$ HindIII fragment of pMP18/MG2H (Figure 1A). To create pSP65/G4HG2, the $0.5 \mathrm{~kb}$ HindIII fragment of pMP18/ $\mathrm{MG} 2 \mathrm{H}$ was ligated into the $4.1 \mathrm{~kb}$ HindIII fragment of pSP65/248. Recombinants were screened by restriction digest (Figure 1B). The identities of both constructions were verified by sequencing the region encoding the junction between the glycinin acidic and basic chains (Chen and Seeburg, 1985).

\section{Construction of $p S P 65 / 248$ Met1, pSP65/248 Met2,3 and $p S P 65 / 248$ Met1,2,3 plasmids}

All plasmids were derived from $p S P 65 / 248$ which originated from a fusion between pSP65 and $p G 248$ (Dickinson, 1988; Dickinson et al., 1989). Mutagenesis was carried out according to the method of Marotti and Tomich (1989) and the synthetic oligonucleotides 5'GCA CCTTGA CC3' and 5'CAGTGTGATCTATGTGACTCGAGG3'. The underlined bases represent changes, and the template used was the $p M P B$ plasmid. The mutated plasmid was transformed in E. coli 1190 and the transformants screened with the mutated oligonucleotides using colony hybridization. After transformation the transformation membranes were washed in $5 \mathrm{X} \mathrm{SSC}$ and $0.1 \% \mathrm{SDS}$ at $45{ }^{\circ} \mathrm{C}$ and the transformants giving strong hybridization signals were selected as putative mutants. The identity of mutants was confirmed by dideoxynucleotide sequencing of the double stranded plasmid. The frequency of mutagenesis was about $2 \%$. The first mutation was at position 1163 where methionine (ATG) replaced lysine (AAG), the second was at position 1311 where methionine (ATG) replaced isoleucine (ATT), and the third was at position 1353 where methionine (ATG) replaced valine (GTG) (Figure 2).

Three plasmids were constructed with an increasing number of methionine residues. Plasmid pSP65/248 Metl was made by deleting the sequence between the $A c c 1$ and $X$ ho $l$ in $p S P 65 / 248$ and exchanged with the sequence between Acc I and Xho $l$ in pMP18/G4 Metl (Figure 3A). Plasmid $p S P 65 / 248$ Met2,3 was constructed by deleting the 

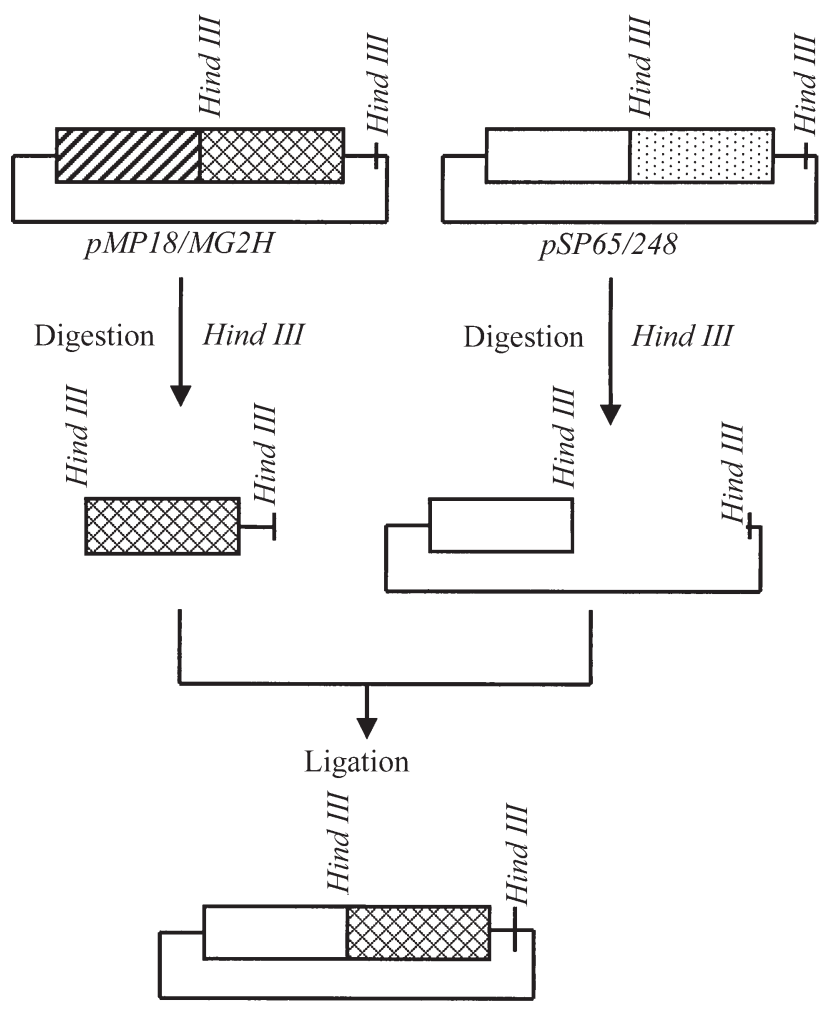

PSP 65/G2HG4

Figure 1 - Construction maps of $p S P 65 / G 2 H G 4$ (A), $p S P 65 / G 4 H G 2$ (B).

$1163 \mathrm{~T}$ (Metl)

385 Cys Thr Leu Lys Leu His Glu Asn Ile Ala Arg Pro +1153 TGC ACC TTG A쓰 CTT CAC GAG AAC ATT GCT CGC CCT Ser Arg Ala Asp Phe Tyr Asn Pro Lys Ala Gly Arg TCA CGC GCT GAC TTC TAG AAC CCT AAA GCT GGT CGC

Ile Ser Thr Leu Asn Ser Leu Thr Leu Pro Ala Leu ATT ACT ACC CTC AAC AGC CTC ACC CTC CCA GCC CTC

Arg Gln Phe Gln Leu Ser Ala Gln Tyr Val Val Leu CGC CAA TTC CAA CTC AGT GCC CAA TAT GTT GTC CTC

$$
1311 \underline{G}(\text { Met2) }
$$

Tyr Lys Asn Gly Ile Tyr Ser Pro His Trp Asn Leu TAG AAG AAT GGA ATT TAG TCT CCA CAT TGG AAT CTG

$$
\stackrel{\longrightarrow}{1353 \mathrm{~A}(\text { Met3) }}
$$

Asn Ala Asn Ser Val Ile Tyr Val Thr Arg Gly GIn AAT GCA AAC AGT GTG ATC TAT GTG ACT CGA GGA CAA

Gly Lys Val 459

GGA AAG GTT -1377

Figure 2 - Nucleotide and amino acid sequence comparisons of Gy 4 genes and proteins. Only nucleotides +1153 to +1377 and translated amino acids 385 to 459 are shown. Arrows refer to the nucleotides that have been mutated in the Gy4. +1153 and +1377 mean the order of these nucleotides from the start code ATG.

sequence between HindIII site in $p S P 65 / 248$. This deletion was filled with the sequence between the HindIII in pMP18/G4Met2,3 and HindIII in the polylinker of pMP18 (Figure 3B). Plasmid $p S P 65 / 248$ Metl,2,3 was produced by deleting the sequence between the HindIII site in pSP65/248 Metl and HindIII in pSP65 polylinker. This deleted sequence was filled with the sequence between the

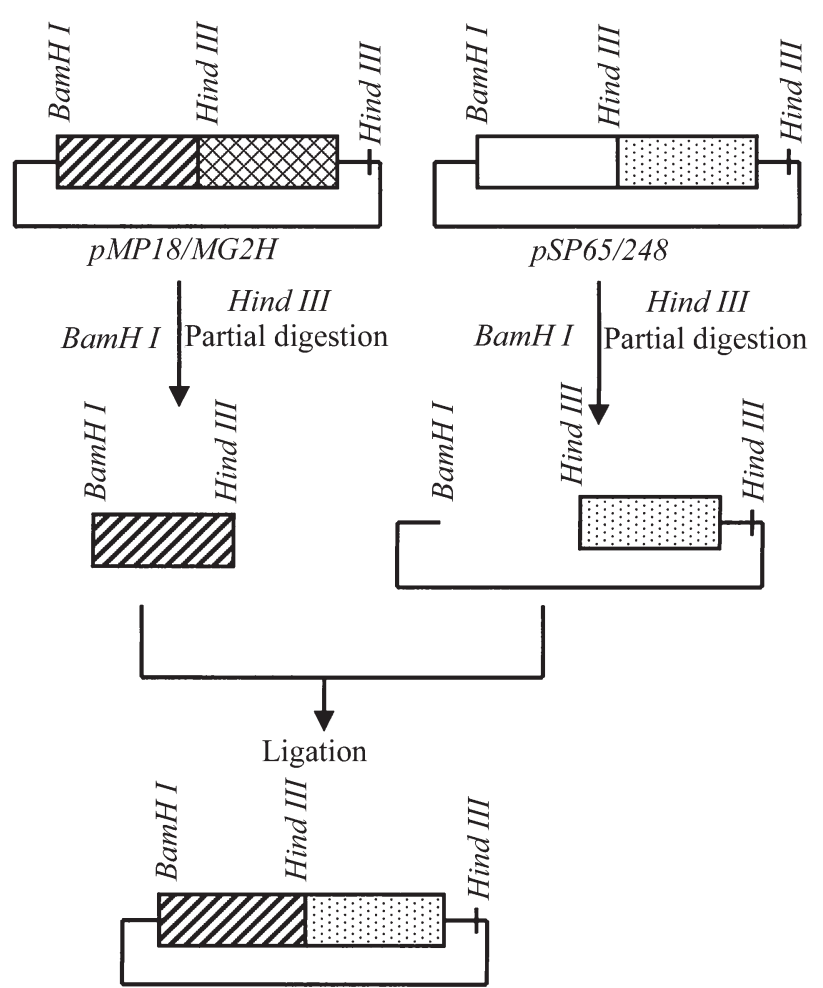

$P S P 65 / G 4 H G 2$

HindIII in pMP18/G4Met2,3 and HindIII in the pSP65 polylinker (Figure 3C).

DNA sequence analysis, sucrose gradient fractionation, trichloroacetic (TAC) precipitation, and SDS-polyacrylamide gel electrophoresis (SDS-PAGE)

Nucleotide sequence analysis was carried out by the chemical method of Maxam and Gilbert (1984). Synthetic oligonucleotides 5'GCGAGACAAGAAACGGGGTTGA GG3' and 5'GAGAACATTGCTCGCCCTTCGCGC3' were used as primers for sequencing across the Gy4 regions.

Assembly was assayed by layering $100 \mu \mathrm{L}$ samples of the in vitro synthesis reaction onto $11 \mathrm{~mL}$ linear 7-25\% sucrose density gradient as described by Dickinson (1988).

Trichloroacetic precipitation was carried out according to the method reported by Dickinson et al. (1987) in which $100 \mu \mathrm{L}$ assembly samples of each mutant were mixed with $25 \mathrm{~mL}$ of $25 \%$ hydrogen peroxide and incubated at $37^{\circ} \mathrm{C}$ for $10 \mathrm{~min}$, after which $1.5 \mathrm{~mL}$ of $25 \%$ TCA and $2 \%$ of casamino acids were added and the mixture stirred and placed on ice for at least $30 \mathrm{~min}$. Samples were collected on glass fiber filters, washed twice with $10 \mathrm{~mL}$ of $10 \%$ TCA and again with $5 \mathrm{~mL}$ of ethanol. The filters were then dried and the radioactivity assessed in $10 \mathrm{~mL}$ of ACS scintillation fluid (Amersham, USA). 

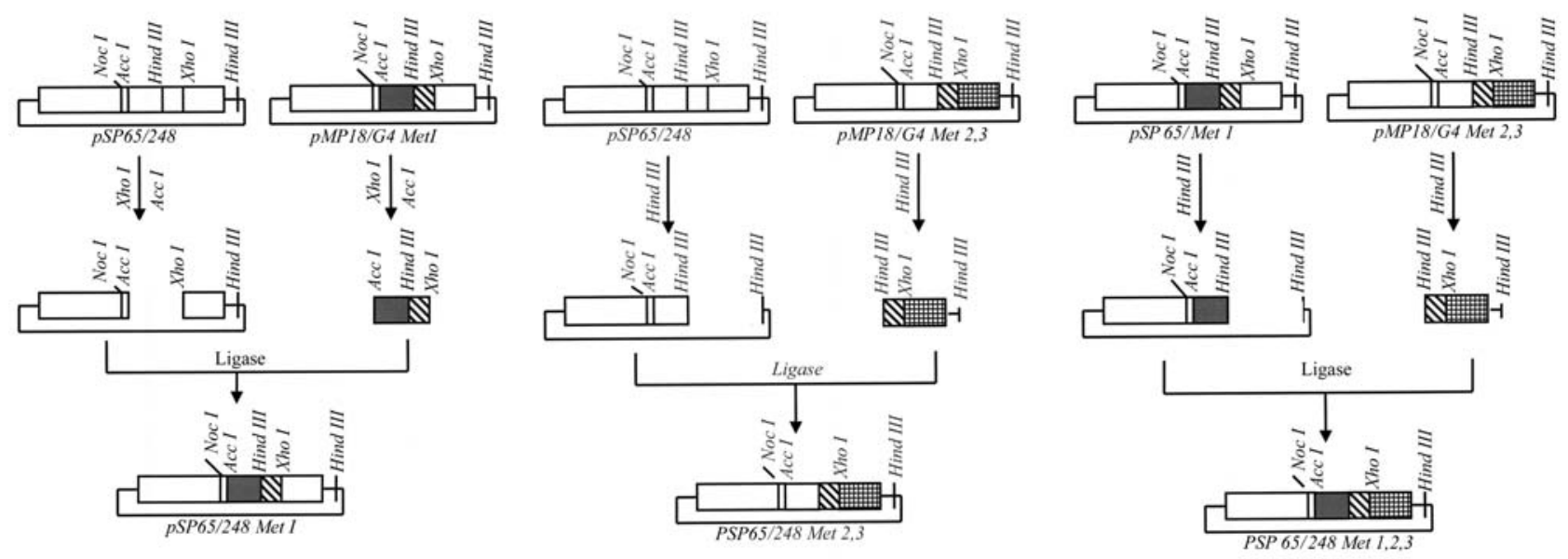

Figure 3 - Construction maps of $p S P 65 / 248 \mathrm{Metl}$ (A), pSP65/248 Met2,3, (B), pSp65/248 Metl,2,3 (C).

Electrophoresis was performed on 12\% (w/v) SDSpolyacrylamide gels (Laemmli, 1970). The 9S assembly fractions from each mutant were pooled and dialyzed against sample buffer $(0.03 \mathrm{M}$ Tris-HCl, $\mathrm{pH} 6.8,2 \%$ (w/v) SDS, $2 \%(\mathrm{w} / \mathrm{v})$ mercaptoethanol, $2.5 \mathrm{M}$ urea and $10 \%$ glycerol), boiled for $2 \mathrm{~min}$ and then loaded onto gels and electrophoretically separated. After electrophoresis gels were stained with Coomassie Blue, and when appropriate, treated with EN $^{3}$ HANCE (New England Nuclear, USA) and visualized using autoradiography.

\section{Results and Discussion}

Two approaches were adopted to increase the number of sulfur ammo acid residues in the G4 subunit, the subunit which assembles both in vivo and in vitro. The first approach adopted was to exchange the acidic and basic domains of the G4 and G2 subunits, while the second approach was to make a number of point mutations in the acidic region (which tolerates conservative point mutations) of the cloned cDNAs encoding G4 group-2 proglycinin subunits.

Dickinson et al. (1987) showed that the G4 and G5 group-2 proglycinin subunits were capable of selfassembly into trimers but the group-1 proglycinin G2 unit was not, even though it was capable of reassembling with mature glycinin much like the G4 and G5 subunits (Dickinson, 1988). Because the group-1 proglycinin G2 subunit is rich in sulfur amino acids the fact that this subunit is not subject to in vitro assembly makes the production of transgenic soybean lines rich in sulfur amino acids more difficult, the production of such lines being the most important factor in increasing the nutritional quality of soybean seed proteins. However, understanding the structural features contributing to the different assembly patterns of group-1 and group-2 glycinins will pave the way to engineering transgenic soybean lines producing seed proteins with enhanced nutritional properties.
In this research I constructed chimeric G2 and G4 subunits to determine the structural features contributing to the different assembly patterns of group-1 and group-2 glycinins. A precedent for this approach is the work of Dickinson et al. (1987) who exchanged the acidic and basic chains of the G4 and G5 group-2 glycinins and found that the modified subunits assembled normally, indicating that in this case the acidic and basic polypeptides are functionally interchangeable.

Figure 4 shows that mutant subunits of the expected size were obtained after transcription of the plasmids and translation in a reticulocyte lysate. The concentration of G2HG4 subunits produced in vitro was low, similar to that of $\mathrm{G} 2$ produced from $p S P 65 / 27$ (Dickinson, 1988). This is important because assembly has been shown to be concentration dependent (Dickinson et al., 1987). In both cases, the low subunit concentration was not due to a lack of mRNA (data not shown).

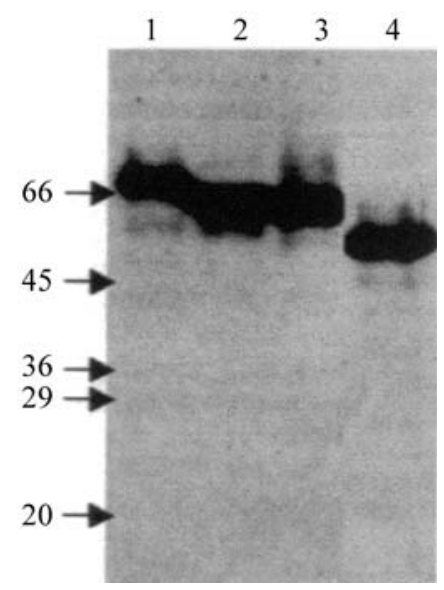

Figure 4 - Electrophoretic separation of G2/G4 fusions synthesized in vitro. Lane 1: G4 synthesized protein using plasmid $p S P 65 / 248$; Lane 2\&3: G2HG4 synthesized protein using plasmid $p S P 65 / G 2 H G 4$; Lane 4: G4HG2 synthesized protein using plasmid $p S P 65 / G 4 H G 2$. Protein standards are given. 
The concentration of fusion G2HG4 was not normally high enough to be tested for self-assembly $(0.74 \mathrm{ng} / 50 \mu \mathrm{L})$ but by increasing the concentration of labeled amino acids in the translation reaction a higher concentration of the G2HG4 subunit was achieved and the subunit was capable of selfassembly into complexes which sedimented as if they were trimers, although the high levels of unincorporated label complicate the interpretation of the result (data not shown). In the case of the $\mathrm{G} 4 \mathrm{HG} 2$ reciprocal fusion the concentration of subunits produced in vitro was $5 \mathrm{ng}$ per $50 \mu \mathrm{L}$, high enough to ensure that self-assembly would occur if it were structurally possible, but no assembled products were observed, suggesting that the G4HG2 fusion product has a structural defect which prevents self-assembly.

It was important to determine whether or not the chimeric proglycinin monomers would re-assemble into hexamers together with mature glycinin subunits that had been dissociated. However, this type of assay is less sensitive to subunit concentration because the large excess of mature dissociated glycinin subunits promotes assembly. Figure 5 shows the results of a typical experiment and it can be seen that after re-assembly with G2HG4 the distribution of radioactivity in the sucrose gradient was similar to that observed when the G4 proglycinin was used. By contrast, the distribution of radioactivity observed when G4HG2 monomers were used was different in that most of the radioac-

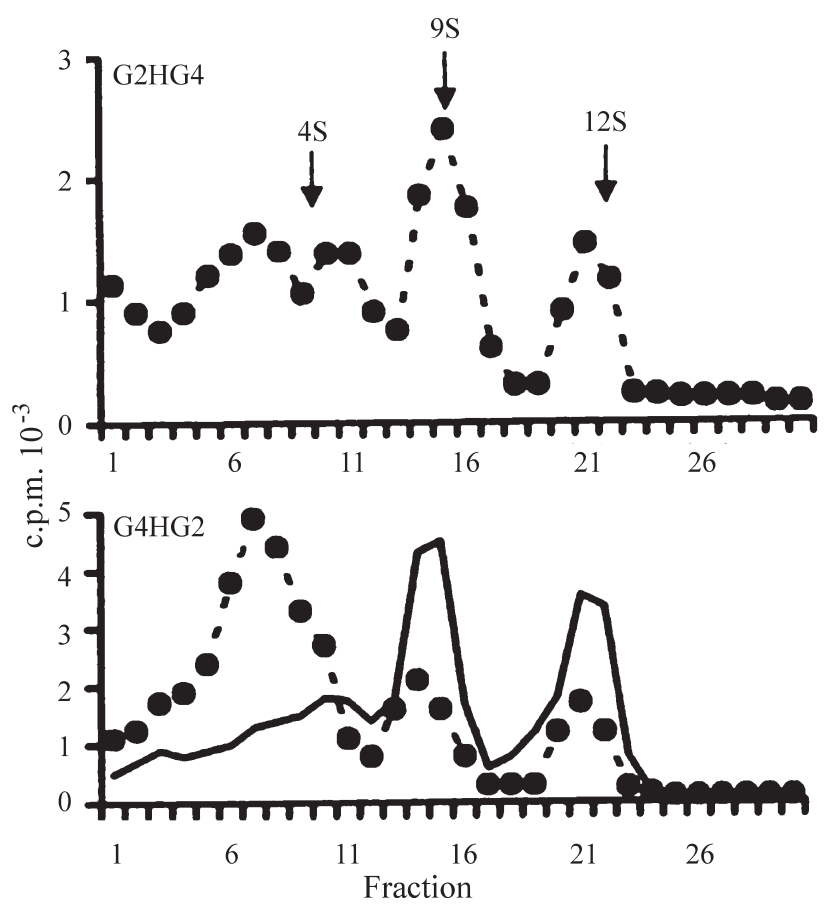

Figure 5 - Radioactively labeled G4, G2HG4 or G4HG2 proglycinins in $0.4 \mathrm{M} \mathrm{NaCl}$ were incubated with dissociated glycinin subunits for $24 \mathrm{~h}$ at $25^{\circ} \mathrm{C}$. The distribution of radioactively labeled protein was determined following sucrose density gradient centrifugation. The distribution obtained with G4 is shown as a control and is indicated by a solid line. The position of sedimentation standards in the sucrose gradients is shown at the top of the figure. tively labeled G4HG2 subunits remained in the unassembled 3S form, indicating that G4HG2-proglycinin subunits were less capable of re-assembly with mature glycinin than the G2HG4 proglycinin monomers.

Dickinson et al. (1987) reported that the acidic chain of Gy4 can tolerate deletion and insertion in the hypervariable region and the mutant subunits produced by such modifications can assemble and re-assemble in a similar manner to that of the G4 subunit. Based on this I chose the acidic chain of Gy4 to generate a number of mutants (pSP65/248Metl, pSP65/248 Metl,2 and pSP65/248 Metl,2,3, see Figure 3). It is important to note, however, that the basic chain of Gy4 cannot tolerate any modification because deletion of any of the $21 \mathrm{~N}$-terminal amino residues in the basic chain of the Gy4 proglycinin subunit inhibits the assembly into trimers (Dickinson et al., 1987) indicating very clearly the importance of the basic chain for in vitro proglycinin assembly.

Each of the mutant subunits described in this paper was found to be capable of self-assembly (Figure 6 A-D) and analysis of the ${ }^{3} \mathrm{H}$-Leu proteins produced by the selfassembly of each mutant subunit during SDS-PAGE showed that the assembled protein had a molecular weight of 66 kilodaltons (Figure 7).

My study showed that in the re-assembly assays all the glycinin subunits tested assembled efficiently with dissociated purified glycinin, although in the self-assembly assays there were differences in assembly pattern between some of the subunits. It is known that the group-2 G4 and G5 glycinin subunits self-assemble into trimers (Dickinson et al., 1987), although the significance of this observation is difficult to evaluate because a similarly modified group-1 glycinin subunit apparently assembles into 9S oligomers when produced in E. coli (Utsumi et al. 1988). The inability

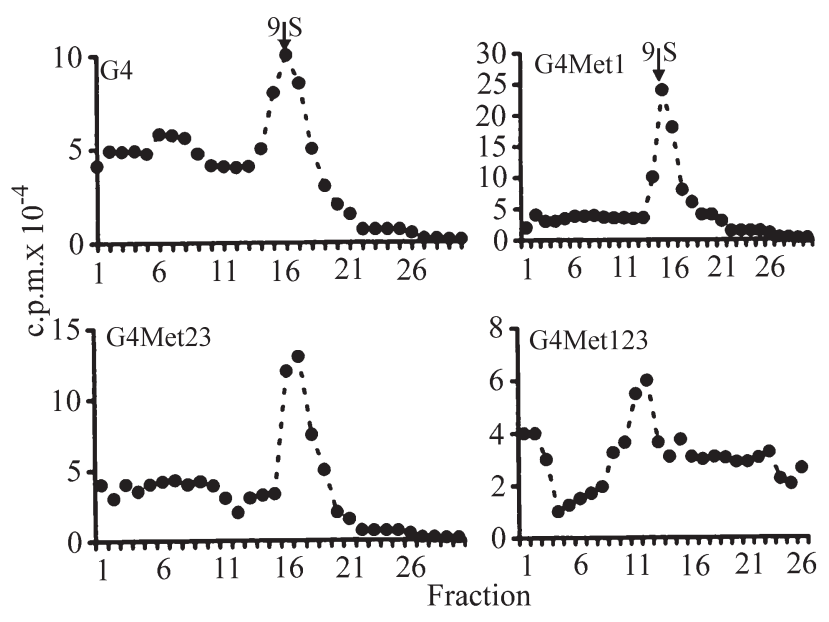

Figure 6 - Self-assembly of pSP65/248, pSP65/Metl, pSP65/Met2,3, pSP65/248 Metl,2,3. Radioactive $\mathrm{H}^{3}$-Leu labeled proglycinins were synthesized in vitro using pSP65/248, pSP65/Metl, pSP65/Met2,3, pSP65/248 Metl,2,3. They were incubated in the translation mixtures for $30 \mathrm{~h} 250{ }^{\circ} \mathrm{C}$ to promote self-assembly and then analyzed by sedimentation in sucrose gradients. 


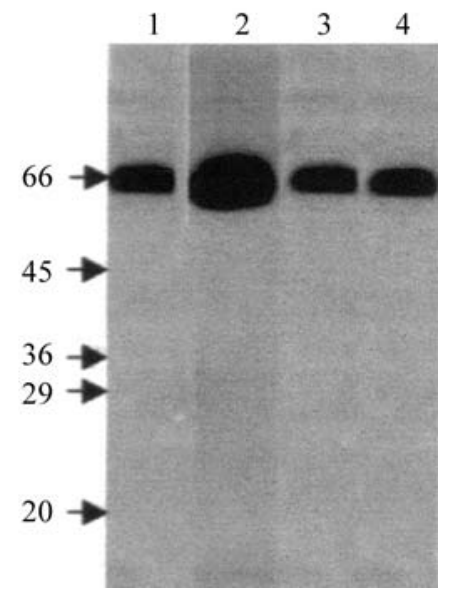

Figure 7 - Electrophoretic separation of G4, Mutant Metl, Mutant Met2,3 and Mutant Metl,2,3 synthesized in vitro. Lane 1: G4 synthesized protein using plasmid $p S P 65 / 248$; Lane 2: Metl synthesized protein using plasmid pSP65/248 Metl; Lane 3: Met2,3 synthesized protein using plasmid pSP65/248 Met2,3; Lane 4: Met1,2,3 synthesized protein using plasmid pSP65/248 Metl,2,3. Size of the protein markers is given in KDa.

of the G2 subunit to self-assemble is unlikely to be due to improper folding because these subunits are able to form mixed oligomers when assembled in the presence of either G4 or G5 (Dickinson, 1988). More probably, the failure to self-assemble reflects structural differences between subunits, which cause them to have different conditions for optimal assembly. Self-assembly of the G2 subunit may be possible with accessory proteins or a higher subunit concentration, either of which may be provided in the E. coli system.

One obvious difference between the group- 1 and group-2 subunits is the size of the hypervariable region, which is much larger in group-2 subunits than group-1 subunits. This structural difference could be related to differences in the assembly properties of the subunits, although this is unlikely because deletion of the entire hypervariable region from the G4 group-2 subunit does not prevent selfassembly into trimers (Dickinson et al., 1990). This indicates that differences in the size of the hypervariable region between glycinin subunits will have little apparent effect on subunit assembly and that the defect, which prevents group-1 self-assembly, lies elsewhere in the protein.

The G2 and G4 glycinin subunits are known to have different in vitro assembly properties, and I evaluated the structural relationships between these subunits by in vitro fusion of the $\mathrm{G} 2$ acidic domain and the $\mathrm{G} 4$ basic domain or the $\mathrm{G} 4$ acidic domain and the G2 basic domain and then tested the fusion products in assembly assays. The selfassembly properties of the chimeric G2HG4 and G4HG2 subunits provided insight into the roles of the acidic and basic polypeptides in subunit interaction. Each fusion protein exhibited assembly characteristics most similar to the protein that donated the basic polypeptide, with the G2HG4 chimera being capable of trimer formation as was the case with the G4 subunit while the G4HG2 chimera was unable to form trimers not as was the G2 subunit (Dickinson, 1988). Dickinson et al. (1987) showed that the same is true for similar fusions between G4 and G5, with G4HG5 assembling more slowly than G5HG4 in the same way as G5 assembled more slowly than G4. These data generally support the hypothesis that the basic polypeptide contains the structural features important in trimer formation (Dickinson et al., 1990).

In my research I produced G2HG4 and G4HG2 monomers in vitro and evaluated them for their ability to assembly with denatured glycinin purified from seeds in a re-assembly assay and found that the majority of G2HG4 monomers re-assembled into trimers and hexamers whereas most G4HG2 subunits remained as monomers. The distribution of radioactively labeled G2HG4 subunits in the sucrose gradient after re-assembly closely resembled the profiles obtained with G2 (Dickinson, 1988) and G4 individually whereas the G4HG2 profile was clearly different. Because the G2 and G4 subunits assembled effectively whereas the G4HG2 subunit did not it is reasonable to infer that the acidic and the basic domains are not independent structural units and that interactions must occur between these domains that are crucial for assembly and possibly for proper folding. This complicates the conclusions drawn from the experiments involving the self-assembly of the G4HG2 subunit, which may fail to self-assembly because it contains the basic domain which prevents self-assembly of the $\mathrm{G} 2$ subunit. It is therefore tempting to conclude that the basic polypeptide contains structures which determine the self-assembly behavior of glycinin subunits, although such a conclusion is probably unsound in the light of the reassembly results obtained with this protein and a more likely explanation of the self-assembly pattern is that the chimeric subunit contains a structural defect as a consequence of the fusion.

Structural differences exist between group-1 and group-2 subunits that influence their functional properties and could have important implications in efforts to engineer glycinin subunits which could be used for improving the nutritional quality of seeds. Because the G2 subunit has a higher sulfur content than the other glycinin subunits it was initially considered to be the best candidate adding additional sulfur ammo acid residues. The fact that this subunit does not self-assemble in vitro (Dickinson, 1988) could mean that a modified G2 subunit expressed at high levels will not assemble efficiently in protein bodies. It also remains to be demonstrated that in vitro and in vivo assembly are equivalent and an alternate and perhaps better strategy for improving the nutritional quality of soybean seeds may be to alter those subunits capable of in vitro selfassembly.

These considerations caused me to turn my attenuation towards modification of the G4 subunit, which selfassembles in vitro and can tolerate modification of its 
hypervariable region with minimal detrimental effect upon the structure of the protein (Nielsen, 1996; Utsumi et al., 2002). I created a number of point mutations in cDNA encoding the G4 subunit and found that the mutant subunits produced self-assembled in vitro as expected, although the assembly pattern was not the same for all mutant subunits. The pSP65/248metl and pSP65/248met23 plasmids produced mutant proglycinins that assembled in a similar manner to proteins produced by the $p S P 65 / 248$ plasmid which contains Gy4 cDNA but the mutant pSP65/248metl23 plasmid produced mutant proglycinin subunits which did not assemble into trimers, from which it can be inferred that the failure of these mutant subunits to form trimers was due to a structural defect as a consequence of miss-folding. The mutations do, however, have wide-ranging effects on the ability of the protein to fold to its native structure, and hence are assumed to affect the stability or structure of a folding intermediate (Chen et al., 1994). It can be concluded that although the acidic subunit of the proglycinin G4 can tolerate deletion and modification without having any effect on assembly, the triple mutation in this domain may disrupt protein folding, such folding being dependent on the presence of acidic and basic subunits. However, the conclusion that limited types of changes targeted at the hypervariable region does not seem to perturb the assembly process (Nielsen 1996) is not supported.

The data presented in this paper suggest that beneficial modification of soybean storage protein subunits might not be as difficult as previously imagined, although all such the modifications must be tested in vivo. The many reports demonstrating that soybeans can be transformed using either disarmed a Ti plasmid or by ballistic methods (Hinchee et al., 1988; Austin and Cress, 1994; Chengsong et al., 1999; Droste et al., 2000.) now make such experiments feasible.

\section{References}

Austin HA and Cress WA (1994) The detection of agro-bacterial Ti transformation in soybean. S A J Sci 90:299-302.

Badley RA, Atkinson D, Hauser H, Oldani D, Green JB and Stubbs JM (1975) The structure, physical and chemical properties of the soybean protein glycinin. Biochim Biophys Acta 412:214-228.

Beilinson V, Chen Z, Shoemaker RC, Fischer RL, Goldberg RB and Nielsen NC (2002) Genomic organization of glycinin genes in soybean. Theor Appl Genet 104:1132-1150.

Chen EY and Seeburg PH (1985). Super-coil sequencing: A fast method for sequencing plasmid DNA. DNA 4:165-170.

Chengsong ZHU, Heping GU and CHEN Xin (1999) Advances in the genetic engineering of insect-resistant soybeans. Soybean Sci 18:260-264.

Cho T-J, Davies CS and Nielsen NC (1989) Inheritance and organization of glycinin genes in soybean. Plant Cell 1:329-337.

Chrispeels MJ, Higgins TJV and Spencer D (1982) Assembly of storage protein oligomers in the endoplasmic reticulum and processing of the polypeptides in the protein bodies of developing cotyledons. J Cell Biol 93:306-313.
Dickinson CD, Floener LA, Lilley GG and Nielsen NC (1987) Self-assembly of proglycinin and hybrid proglycinin synthesized in vitro from cDNA. Proc Natl Acad Sci USA 84:5525-5529.

Dickinson CD (1988) Assembly properties of glycinin subunits: Development of a novel in vitro assembly assay. $\mathrm{Ph} \mathrm{D}$. Thesis, Purdue University, West Lafayette, Indiana.

Dickinson CD, Hussein HA and Nielsen NC (1989) Role of posttranslational cleavage in glycinin assembly. Plant Cell 1:459-469.

Dickinson CD, Scott MP, Hussein EHA, Argos P and Nielsen NC (1990) The effect of structural modifications on the assembly of a glycinin subunit. Plant Cell 2:403-413.

Droste A, Pasquali G and Bodanese-Zanettini HM (2000) Integrated bombardment and Agrobacterium transformation system: An alternative method for soybean transformation. Plant Mol Biol Rep 18:51-59.

Goldberg RB, Hoschek G, Tarn SH, Ditta GS and Breidenbach RW (1989a) Abundance, diversity and regulation of mRNA sequence sets in soybean embryogenesis. J Dev Biol 83:201-217.

Goldberg RB, Hoschek G, Tarn SH, Ditta GS and Breidenbach RW (1989b) Developmental regulation of clone super abundant embryo m RNAs in soybean. J Dev Biol 83:218-231.

Hinchee MA, Conner-Ward DV, Newell CA, McDonnell RE, Sato SJ, Gasser CS, Fischhoff DA, Re DB, Fraley RT and Horsch RE (1988) Production of transgenic soybean plants using Agrobacterium-mediated DNA transfer. Biotechnology 6:915-922.

Jung R, Scott MP, Nam Y-W, Beaman TW, Bassuner R, Saalbach I, Miintz K and Nielsen NC (1998) The role of proteolysis m the processing and assembly of $11 \mathrm{~S}$ seed globulins. Plant Cell 10:343-357.

Katsube T, Gidamis AB, Kanamori J, Kang IJ, Utsumi S and Kito M (1994) Modification tolerability of the hypervariable region of soybean proglycinin. J Agric Food Chem 42:26392645.

Katsube T, Kang IJ, Takenaka Y, Adachi M, Maruyama N, Morisaki T and Utsumi S (1998) N-Glycosylation does not affect assembly and targeting of proglycinin in yeast. Biochim Biophys Acta 1379:107-117.

Kim C-S, Kamiya S, Kanamori J, Utsumi S and Kito M (1990) High-level expression, purification and functional properties of soybean proglycinin from Escherichia coli. Agric Biol Chem 54:1543-1550.

Kinney AJ, Jung R and Herman EM (2001) Cosuppression of the subunits of $\beta$-conglycinin in transgenic soybean seeds induces the formation of endoplasmic reticulum-derived protein bodies. Plant Cell 13:1165-1178.

Kunkel TA (1985) Rapid and efficient site-specific mutagenesis without phenotypic selection. Proc Natl Acad Sci USA 82:488-492.

Laemmli UK (1970) Cleavage of structural proteins during the assembly of the head bacteriophage T4. Nature 227:680-685.

Larkins BA (1981) Seed storage proteins. In: Stumpf Pk and Conn EE (eds) Biochemistry of Plants: A Comprehensive Tretise, v. 6. Academic Press, New York, pp 449-489.

Marroit KR and Tomich C-SC (1989) Simple and efficient oligonucleotide - Directed mutagenesis using one primer and circular plasmid DNA template. Gene Anal Techn 6:67-70. 
Maxam AM and Gilbert W (1984) Sequencing end-labeled DNA with base-specific chemical cleavages. Methods Enzymol 65:409-560.

Moreira MA, Hermodson M, Alarkins BA and Nielsen NC (1979) Partial characterization of the acidic and basic polypeptides of glycinin. J Biol Chem 254:9921-9926.

Nielsen NC (1984) The chemistry of legume storage proteins. Philos Trans R Soc Lond B Biol Sci 304:287-296.

Nielsen NC, Dickinson CD, Cho TJ, Thanh VH, Scallon BJ, Fischer RL, Sims TL, Drews GN and Goldberg RJ (1989). Characterization of the glycinin gene family in soybean. Plant Cell 1:313-328.

Nielsen NC (1996) Soybean seed composition. In: Verma DPS and Shoemaker RC (eds). Soybean: Genetics, Molecular Biology and Biotechnology. CAB International, Wallingford, pp 127-164.

Nielsen NC, Bassuner R and Beaman TW (1996) The biochemistry and cell biology of embryo storage proteins. In: Larkins BA and Vasil IK (eds), Cellular and Molecular Biology of Plant Seed Development. Kluwer Academic Publishers, Dordrecht, pp 151-220.
Nielsen NC and Nam Y-W (1999) Soybean globulins. In: Casey R and Shewry PR (eds) Seed Proteins. Kluwer Academic Publishers, Dordrecht, pp 285-314.

Turner NE, Thanh VH and Nielsen NC (1981) Purification and characterization of mRNA from soybean seeds. J Biol Chem 257:4016-4018.

Utsumi S, Kim C-S, Sato T and Kito M (1988) Signal sequence of preproglycinin affects production of the expressed protein in Escherichia coli. Gene 71:349-358.

Utsumi S, Gidamis AB, Kanamori J, Kang IJ and Kito M (1993) Effects of deletion of disulfide bonds by protein engineering on the conformation and functional properties of soybean proglycinin. J Agric Food Chem 41:687-691.

Utsumi S, Maruyama N, Satoh R and Adachi M (2002) Structure-function relationships of soybean proteins revealed by using recombinant systems. Enz Micro Technol 30:284-288.

Vitale A and Jurgen D (1999) The endoplasmic reticulum-gateway of the secretory Pathway. Plant Cell 11:615-628.

Walling L, Drews GM and Goldberg RB (1986) Transcriptional and post-transcriptional regulation of soybean seed protein mRNA levels. Proc Natl Acad Sci USA 83:2123-2127.

Wang TL, Domoney C, Hedley CL, Casey R and Gmsak MA (2003) Can we improve the nutritional quality of legume seeds? Plant Physiol 131:886-891.

Associate Editor: Márcio de Castro Silva Filho 